\title{
MINERAIS DE COLEÇÃO: CIÊNCIA, ESTÉTICA E MERCADO
}

\author{
Luiz Alberto Dias Menezes Filho ${ }^{1}$ \& Mario Luiz de Sá Carneiro Chaves ${ }^{2}$
}

\begin{abstract}
RESUMO
A atividade de colecionar minerais tem milhões de aficionados em todo o mundo, mas infelizmente apenas algumas centenas no Brasil. O comércio desses minerais movimenta por ano algumas dezenas de milhões de dólares, proporcionando renda e condições de subsistência a regiões pobres do Brasil e de outros países. Esse mercado também incentiva a produção em pequenos depósitos minerais e isso tem permitido a descoberta e a preservação de novas espécies minerais que de outra forma permaneceriam desconhecidas. O Brasil é um dos maiores produtores mundiais de minerais para coleção, entretanto quase que exclusivamente provenientes de atividades de garimpagem. O riquíssimo patrimônio mineralógico contido em jazidas de grandes minerações industriais tem sido perdido, devido ao desinteresse de tais empresas e seus corpos técnicos em estudar a mineralogia dessas jazidas.
\end{abstract}

Palavras-chave: minerais, coleções, exploração mineral.

\begin{abstract}
The hobby of mineral collecting has millions of adepts all over the world, but only few hundreds in Brazil. The trade of these minerals amount annually some tens of millions of dollars, providing monetary incentive to poor regions in Brazil and in other countries. Such market incentives the exploitation of small mineral deposits and has allowed the discovery and preservation of new mineral species. Brazil is a major producer of minerals for collections, however mostly from the small "garimpo's" services. The very rich mineralogical patrimony from the ore deposits subject to industrial mining has been lost due the lack of interest from the big companies and their technical staffs to study the mineralogy of these deposits.
\end{abstract}

Keywords: minerals, collections, mineral exploration.

\section{INTRODUÇ̃̃̃O}

Os designados "minerais de coleção" em geral são extraídos como um subproduto da atividade mineradora. Por suas características únicas, eles podem ser considerados verdadeiras obras-primas da natureza, e desta maneira adquirem não somente importância científica como também econômica. A demanda gerada por milhões de colecionadores em todo o mundo faz com que o comércio e a exportação de minerais de coleção atinjam cifras vultuosas e, neste contexto, o Brasil se destaca como um grande produtor. No presente artigo procura-se descrever os principais fatores a regularem as ações que permitem desde a descoberta e extração até a exposição final de tais peças em grandes museus e coleções particulares de todo mundo, além da importância do conhecimento das espécies minerais brasileiras como mais um patrimônio natural a ser preservado.

\section{DEFINIÇÃO E PRINCIPAIS ASPECTOS DOS MINERAIS DE COLEÇÃO}

De modo simplificado, os minerais são reconhecidos como elementos ou compostos químicos sólidos de origem natural, de composição química e estrutura cristalina definidas, formados como produtos de processos inorgânicos (Betejtin, 1977; Gary et al., 1973). Atualmente são descritos pela ciência cerca de
4.400 espécies minerais, mas este número tem crescido entre 30-50 novas espécies por ano (Mandarino \& Back, 2004). De tal montante, cerca de 2.500 minerais são extremamente raros apresentando-se em pouquíssimas ocorrências (e muitos deles em somente um local); outros 1.200 aparecem com alguma maior freqüência na crosta terrestre, porém somente uns 400 podem adquirir importância econômica relevante em atividades mineradoras.

Entretanto, para que uma amostra mineral venha ser de interesse e valor para museus e colecionadores é necessário que ela tenha alguns dos atributos descritos a seguir:

- Beleza - é o fator mais importante que leva o colecionador a desejar adquirir um mineral e também, conseqüentemente, o aspecto fundamental na determinação do preço de uma amostra. A beleza decorre da combinação de vários fatores, como cor, brilho e forma geométrica natural, que se arranjem harmonicamente (a exemplo dos rutilos dourados intercrescidos com placas de hematita, mostrados na figura 1). No entanto, este não é o único fator, devendo ainda ser observados diversos outros requisitos (descritos em seqüência);

- Raridade - é um fator quase tão importante quanto a beleza. Minerais comuns como calcita, ametista, etc., mesmo muito bonitos e em espécimes de maior

1 - Luiz Menezes Comércio e Exportação de Minerais Ltda, Belo Horizonte. E-mail: Imenezesminerals@uol.com.br 2 - CPMTC-IGC/UFMG, Pesquisador CNPq, Belo Horizonte. E-mail: mchaves@igc.ufmg.br 



Figura 1: Agregados de rutilo dourado intercrescidos com placas de hematita especular, sobre matriz de tufo vulcânico (Novo Horizonte - BA). Abaixo, detalhe de uma pequena amostra de coleção isolada, obtida com material da mesma localidade (Fotos L. Menezes Filho).

porte, podem valer menos do que pequenas e belas amostras de topázio ou turmalina, mais difíceis de serem encontradas. Assim, minerais raríssimos na natureza, a exemplo da kosnarita $-\mathrm{KZr}_{2}\left(\mathrm{PO}_{4}\right)_{3}$ - descoberta em 1997 nos Estados Unidos, depois encontrada em um pegmatito na Austrália e em 2003 num outro de Minas Gerais, mesmo sem serem excepcionais podem ser muito valorizados (Figura 2);

- Tamanho - atendidas as condições anteriores, o tamanho passa a ser o fator determinante. De tal modo, amostras maiores, de qualidade equivalente, valerão sempre mais do que peças de porte menor;

- Presença de matriz - são especialmente apreciados pelos colecionadores os cristais que naturalmente se incrustam na rocha ou mineral matriz, que denuncie sua gênese (como a presença de feldspato em amostras de origem pegmatítica). Isso torna muito importante a quem está coletando um mineral, que faça todos os esforços necessários para extrair os espécimes preservando pelo menos parte dessa matriz. Também é desejável que ocorra uma proporção harmoniosa entre o tamanho do cristal e o da matriz, como no caso da brazilianita sobre muscovita da figura 3;

- Estado de conservação da amostra - os cristais devem ser extraídos, transportados e manuseados com o necessário cuidado para impedir que suas arestas sejam quebradas, o que as desvalorizaria de modo dramático. Tanto os museus mundiais como colecionadores sérios unca comprarão uma amostra com pontas ou arestas danificadas.

\section{TIPOS E OBJETIVOS DAS COLEÇÕES}

Os parâmetros explicitados no item anterior determinam não só os aspectos econômicos como também os geológicos dos minerais de coleção, pois são necessárias condições termodinâmicas especiais e quase únicas para a geração de tal estado de perfeição. Embora alguns museus e mesmo colecionadores particulares não coloquem 


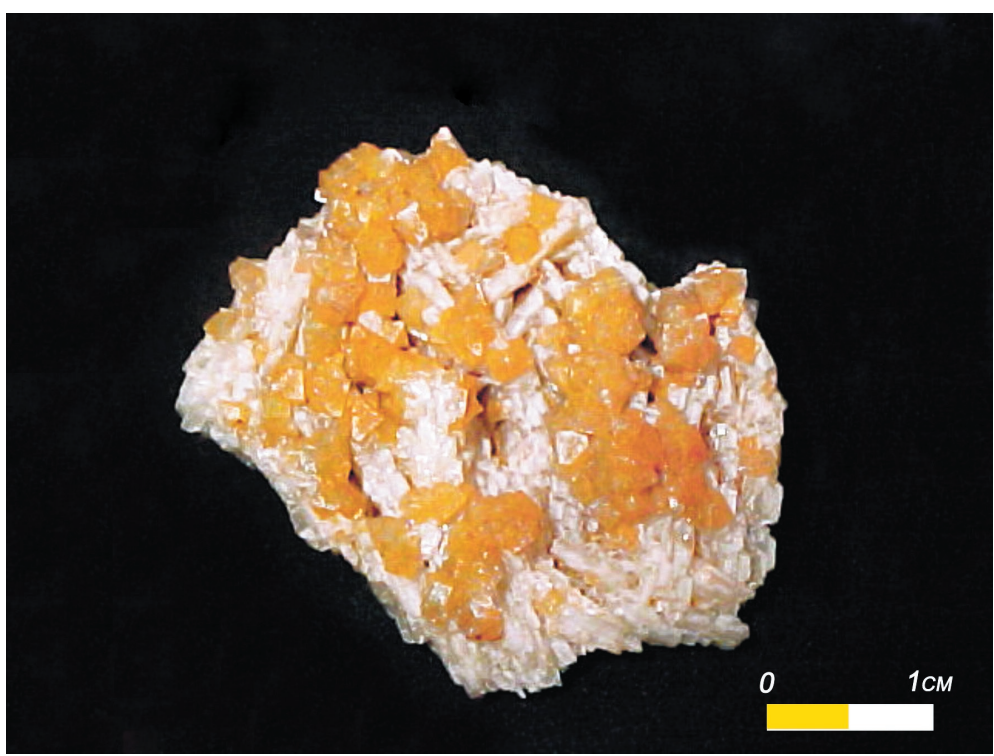

Figura 2: Agregado de cristais de kosnarita, incrustado sobre matriz de albita (Lavra do Jenipapo, Itinga - MG). A kosnarita foi descrita primeiramente em 1997 nos EUA, mas até então só era conhecida na forma de microcristais (Foto L. Menezes Filho).

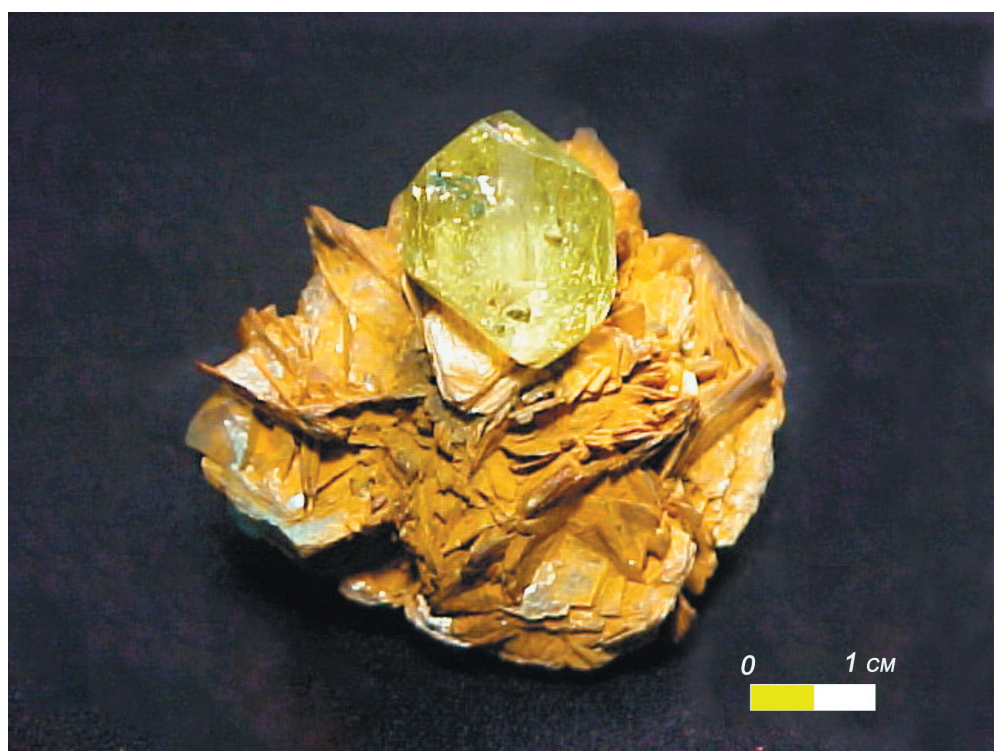

Figura 3: Cristal perfeito de brazilianita, biterminado, crescido sobre agregado de cristais de muscovita (Foto L. Menezes Filho). Esse mineral foi descoberto na Lavra do Córrego Frio, Divino das Laranjeiras - MG, na década de 1940, e suas amostras mais representativas adornam museus e coleções de todo mundo, restando pouquíssimos exemplares de boa qualidade no Brasil.

limites no escopo de seus acervos, tentando incorporar sempre o maior número possível de espécies, bem como amostras de várias procedências de uma mesma espécie, a maior parte das coleções procura impor restrições buscando seu enquadramento dentro de uma temática mais específica. Na maior parte das vezes tal enquadramento visa características de:

- Estética - a grande maioria dos colecionadores é atraída pela beleza dos minerais, que para esses será o atributo essencial;

- Espécies, grupos ou classes minerais - muitos colecionadores buscam também conhecer a composição química dos minerais e sua classificação em grupos ou classes particulares, e podem se interessar em adquirir certas amostras que, mesmo não sendo espetaculares, constituam membros raros de grupos importantes. Por outro lado, outros colecionam minerais (como quartzo, calcita, fluorita, etc.) que mostrem abundância de formas cristalográficas e/ou cores diferentes, ou ainda membros de um grupo (como granadas, micas, turmalinas, zeólitas, etc.), classes de acordo com a composição química (como óxidos, carbonatos, etc.), ou então apenas minerais contendo um certo elemento químico (como minerais de $\mathrm{Cu}, \mathrm{Zn}, \mathrm{Pb}$, etc.);

- Todas as espécies minerais - somente a minoria dos museus e colecionadores se dedica à tarefa de tentar possuir o maior número possível de espécies minerais. 
Como em muitos casos são pouquíssimas as amostras disponíveis, é tarefa quase impossível para qualquer coleção possuir todas as espécies minerais conhecidas. Por exemplo, a nikisherita - $\mathrm{NaFe}_{6} \mathrm{Al}_{3}\left(\mathrm{SO}_{4}\right)_{2}(\mathrm{OH})_{18} .1$ $2 \mathrm{H}_{2} \mathrm{O}$ - descoberta em 2003 na Bolívia, produziu ao todo somente oito amostras;

- País, região ou mina - museus e colecionadores podem restringir seu enfoque a um espaço geográfico particular. Existem coleções de minerais provenientes de apenas um país, algumas vezes de um estado ou região do país, ou até de apenas alguma mina famosa. Um exemplo típico é a mina de Tsumeb, na Namíbia (atualmente desativada), onde foram descritas cerca de 175 espécies e, dentre estas, 23 espécies novas para a ciência (Pinch \& Wilson, 1977);

- Porte - em geral os colecionadores impõem restrições quanto aos tamanhos das amostras. Normalmente as mais valorizadas estão na faixa conhecida no mercado internacional como cabinet size (o "tamanho gabinete", que possui de $5 \times 5 \mathrm{~cm}$ até no máximo $20 \times 20 \mathrm{~cm}$ ), devido às dimensões das vitrines de exibição das coleções. Existem também tendências predominantes para certas regiões: os europeus preferem amostras entre 10-20 cm, enquanto no Japão, devido às limitações de espaço nas residências, dá-se preferência a amostras menores que $10 \mathrm{~cm}$. Já os norte-americanos colecionam praticamente de tudo.

Em relação aos grandes museus, alguns deles, como o de História Natural de Paris, se interessam principalmente por cristais gigantes. Entretanto, milhares de colecionadores, em especial nos Estados Unidos, apreciam apenas amostras que cabem em caixinhas cúbicas de plástico com $3,2 \mathrm{~cm}$ de aresta (thumbnail boxes). De outro modo, em todo o mundo incontáveis colecionadores se interessam por minerais cujos cristais não excedem $3 \mathrm{~mm}$ de comprimento, sobre a rocha matriz medindo até $3 \mathrm{~cm}$ (conhecidos como micromounts), os quais precisam ser observados sob microscópio ou lupa binocular. A grande maioria das espécies recém descobertas se enquadra na categoria dos micromounts

\section{PRODUCC̃̃O E DESTINO DAS AMOSTRAS DE COLEÇÃ̃O}

A grande maioria das amostras de coleção é produzida durante alguma forma de mineração, normalmente constituindo subproduto de uma atividade industrial onde o mineral de coleção não é seu objetivo principal. Assim, a recuperação e preservação dessas amostras dependerão do poder decisório dos profissionais que comandam a operação. Em países mais desenvolvidos sempre houve uma sensibilidade desses profissionais, bem como dos proprietários das minas, quanto ao valor científico dos minerais, entendendo seu valor como patrimônio não só nacional como também da humanidade. Portanto, a maior parte das amostras nos museus e coleções mundiais foi originada em minas industriais, seja nesses países como em atividades conduzidas por empresas multinacionais em países menos desenvolvidos.

Por outro lado, a situação brasileira é bastante peculiar, pois normalmente as grandes empresas reprimem a coleta dos minerais e, quando muito, os profissionais coletam algumas amostras mais vistosas e as levam aos escritórios de geologia ou de gerência de produção. Nesse local, elas são empilhadas até talvez serem doadas a algum visitante, que não terá qualquer noção de como preservá-las ou intenção de estudá-las convenientemente.

Embora quase sempre o valor das amostras de coleção que possam eventualmente ser recuperadas durante a operação de uma mina industrial seja insignificante em comparação com o faturamento da mina, como sua preservação constitui-se numa ação de sensibilidade ecológica e de respeito à natureza, muitas empresas no exterior têm adotado alternativas que resultam não em faturamento direto, mas em benefícios gerais para suas comunidades:

- A já citada mina de Tsumeb (Namíbia), fazia periodicamente leilões de lotes de minerais interessantes coletados durante as operações, e os valores arrecadados eram destinados a um fundo de assistência social;

- A mina Elmwood, no Tennessee (EUA), explotava chumbo e zinco produzindo também belíssimos cristais de calcita laranja, fluorita roxa, galena e esfalerita. Como a mina tinha excesso de capacidade de produção em relação ao seu parque metalúrgico, ao se encontrarem cavidades com minerais cristalizados as operações eram paralisadas e o material cuidadosamente extraído. Os lotes eram periodicamente leiloados e o dinheiro arrecadado dividido ao final do ano entre os funcionários;

- Na mina de cobre Ray, Arizona (EUA), existe uma zona de falha rica em cristais de azurita, bem como massas de azurita/malaquita de qualidade gemológica. Ali, permite-se que um comerciante de minerais faça a coleta desse material, a preço pré-estabelecido, gerando um montante que é disponibilizado ao Arizona-Sonora Desert Museum, do mesmo Estado, visando a aquisição de minerais para seu acervo. Essa empresa está assim patrocinando aquele museu sem qualquer gasto, apenas permitindo que os minerais sejam coletados ao invés de destruídos.

O Brasil durante o século XX certamente foi o maior produtor mundial de amostras para coleção, proveniente quase exclusivamente de garimpos, em especial dos depósitos em pegmatitos da região nordeste de Minas Gerais. A extração desses minerais se realçou durante a Segunda Guerra Mundial, quando o objetivo principal era a produção de mica e quartzo industrial de alta pureza, bem como metais estratégicos (nióbio, tântalo, berílio, urânio/tório e terras raras). O encontro simultâneo de minerais gemológicos, como turmalinas, berilo e topázio, fez que esses, depois da guerra, se tornassem os alvos econômicos prioritários. Os minerais de coleção sempre foram subprodutos e, embora venham sendo coletados e comercializados, o baixo nível cultural dos garimpeiros e a precariedade 
dos métodos, ferramentas e maquinários empregados na extração, tem resultado em danos físicos às amostras e também sua comum remoção sem a rocha/mineral matriz, reduzindo seus valores finais. Assim, apenas em casos raros, onde naturalmente a matriz é de mais fácil remoção, amostras que possuem os atributos ideais são conseguidas.

Como os minerais de coleção de alta qualidade vêm se tornando mais e mais escassos no mundo, seus valores têm gradualmente aumentado. Isto possibilita a condução de pequenos empreendimentos de mineração voltados prioritariamente à produção desses minerais, utilizando tecnologia e maquinário que permitem a extração de cristais na rocha matriz com o mínimo de danos. O caso mais notável a respeito é o da mina Sweet Home, no Colorado (EUA), uma mina de prata de pequeno porte que operou de 1889 até 1980 . Ela foi reaberta em 1990 visando exclusivamente a produção de cristais de rodocrosita vermelhos, os melhores do mundo, como é o exemplo da "Alma King" (Figura 4): um romboedro perfeito de $16 \mathrm{~cm}$ de aresta sobre matriz de quartzo com cerca de $60 \mathrm{~cm}$ (encontrado em 1991), hoje pertencente ao Museu de História Natural de Denver, também no Colorado (Moore, 1998).

Durante o século passado destacaram-se como os maiores produtores mundiais de minerais para coleção:

(1) Brasil - principalmente a província pegmatítica do nordeste de Minas Gerais (incluindo áreas próximas da Bahia e Espírito Santo), que produz quartzo, turmalina, berilo, topázio e minerais raros; jazidas de quartzo na Serra do Espinhaço (Corinto e Diamantina - MG, e Ibitiara - BA); as jazidas de ágata e ametista em derrames basálticos (RS) e a província pegmatítica do Nordeste (PB-RN-CE). Além disso, esporádicas amostras de minas industriais, literalmente "salvas" do britador por conta e risco de funcionários sem autorização das empresas. Entre tais amostras, constituem os casos mais notáveis: scheelita vermelha, apatita rosa, cristais de ouro, quartzo, siderita e dolomita, da mina de Morro Velho, em Nova Lima - MG; magnesita cristalizada, esmeralda, uvita, sellaíta, quartzo geminado segundo a "Lei-do-Japão" e muitos outros minerais raros, das minas da Magnesita SA, em Brumado - BA;

(2) Estados Unidos - quando a mineração esteve no auge (até o início dos anos 80) houve importante produção em minas de cobre (Arizona, Novo México, Utah e Montana), ouro (Califórnia, Colorado e Nevada), prata (Colorado), chumbo/zinco (Tennessee, Illinois e Kansas), zinco (New Jersey) e muitas outras; bem como de pegmatitos principalmente da Califórnia, Colorado, North Carolina, New Hampshire e Maine;

(3) México - em geral de pequenas minas de cobre, chumbo, zinco e prata;

(4) Peru/Bolívia - minas de ouro, prata, chumbo, cobre, zinco, estanho, enxôfre, antimônio e molibdênio;

(5) Austrália - minas de cobre, chumbo, zinco, ferro e ouro;
(6) República Sul-Africana e Namíbia - minas de cobre, chumbo, zinco, manganês, ouro, fosfatos e vanádio;

(7) Canadá - pedreiras de extração de nefelinasienito, além de minas de asbesto, cobre e urânio;

(8) Madagascar, Moçambique, Nigéria, Zâmbia e Tanzânia - minerais de pegmatitos;

(9) Paquistão e Afeganistão-minerais de pegmatitos. A forte ascensão da produção desses minerais a partir das décadas finais do século 20 , de certa forma veio suprir ou mesmo substituir a produção em baixa dos mesmos minerais provenientes de pegmatitos brasileiros (Minas Gerais principalmente);

(10) Índia - minerais do grupo das zeólitas, encontrados em derrames basálticos, além de rubis e safiras;

(11) Sri Lanka e Mianmar - rubis, safiras e espinélios;

(12) Países Europeus - até o final da década de 80 do século passado era importante a produção de minerais de coleção a partir de minas metálicas e de minérios industriais, destacando-se a Inglaterra (fluorita, barita e minerais de estanho), Alemanha (minerais de chumbo, zinco e prata), França (minerais de cobre, urânio e fluorita), Espanha (minerais de chumbo e pirita), Portugal (minerais de estanho, tungstênio e urânio), países Escandinavos (minerais de cobre, chumbo, zinco, prata e ferro) e países do Leste Europeu (minerais de antimônio, chumbo, zinco e prata). Na segunda metade do século, porém, a mineração entrou em forte declínio e atualmente é inexpressiva;

(13) Rússia e China - embora houvesse produção durante todo o século passado, a maior parte das amostras era perdida por falta de estímulo econômico. A partir da década de 1990, no entanto, ambos se tornaram importantes produtores mundiais. A Rússia, com minerais de chumbo, zinco, cromo, platina, prata, terras raras, nióbio, mercúrio, arsênio, quartzo e outros materiais também gemológicos (alexandrita, esmeralda, topázio, turmalina, diamante, etc.); e China, com minerais de cobre, estanho, tungstênio, mercúrio, arsênio, prata e chumbo.

\section{COMÉRCIO DOS MINERAIS DE COLEÇÃO}

Além da preservação de um patrimônio científicomineralógico, a arte de colecionar minerais também pode e deve ser analisada pelo contexto comercial. No Brasil, a enorme produção desses minerais é quase toda voltada para o comércio exterior; em todo o país existem menos que 10 grandes colecionadores. Nos Estados Unidos, entretanto, estima-se em 2 milhões o número de colecionadores de minerais (cerca de $1 \%$ da população), os quais se organizam em centenas de clubes de mineralogia. Muitas cidades (mesmo pequenas) realizam anualmente seus "Gem, Mineral and Fossil Shows", aonde comerciantes locais e nacionais vêm oferecer as novidades produzidas em todo o mundo. Em muitos destes shows, em áreas de exibição 


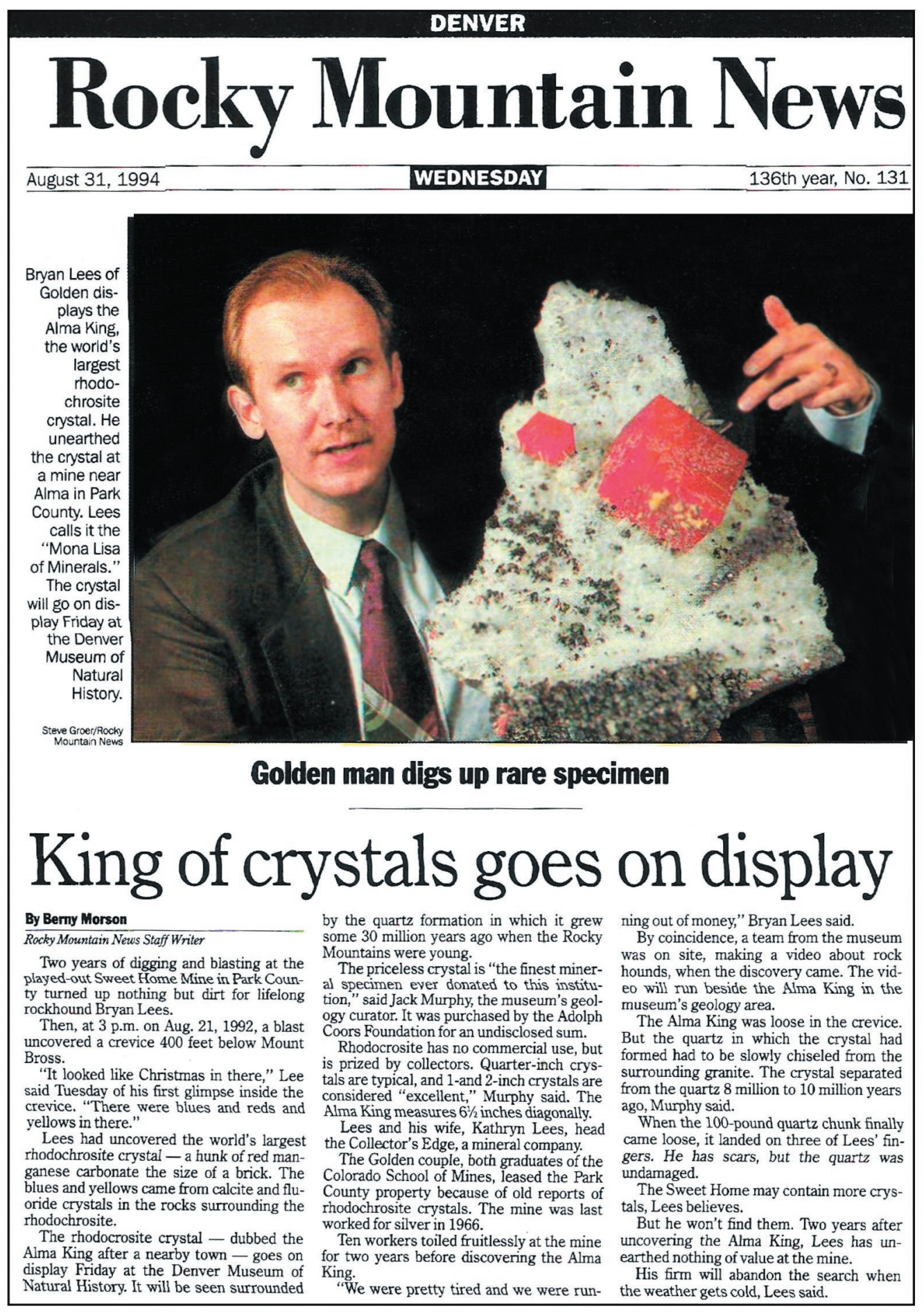

Figura 4: A mina Sweet Home (Califórnia, EUA), é um exemplo de bom tratamento e valorização dado aos minerais de coleção. No local, produz-se as mais finas espécies mundiais de rodocrosita (Moore, 1998), a exemplo da "Alma King” (Alma é o nome do local da mina), motivo de notícia em jornais do país (reproduzida com permissão da Mineralogical Record).

colecionadores e museus expõem amostras relativas a um tema pré-selecionado. Em dois shows anuais de grande porte (Tucson, Arizona, em fevereiro; e Denver, Colorado, em setembro), importantes atacadistas internacionais abastecem o comércio americano e de outros países. Em cada final de semana ocorrem cerca de 4 a 6 destes shows em diferentes partes dos EUA, e neles as crianças podem ter seu primeiro contato com o reino mineral.
Seguem em ordem de importância no comércio de minerais, a Europa Ocidental (destacando Alemanha, França, Itália, Suíça e Espanha), Canadá, Japão e Austrália. Em todos esses países ocorrem também shows de minerais, nos finais de semana, mas em quantidade menor do que nos EUA. Na Europa destacam-se dois grandes eventos: o de Sainte-Marie aux Mines (França), em junho, e o de Munique (Alemanha), em outubro, onde além da venda de minerais ao público, atacadistas 


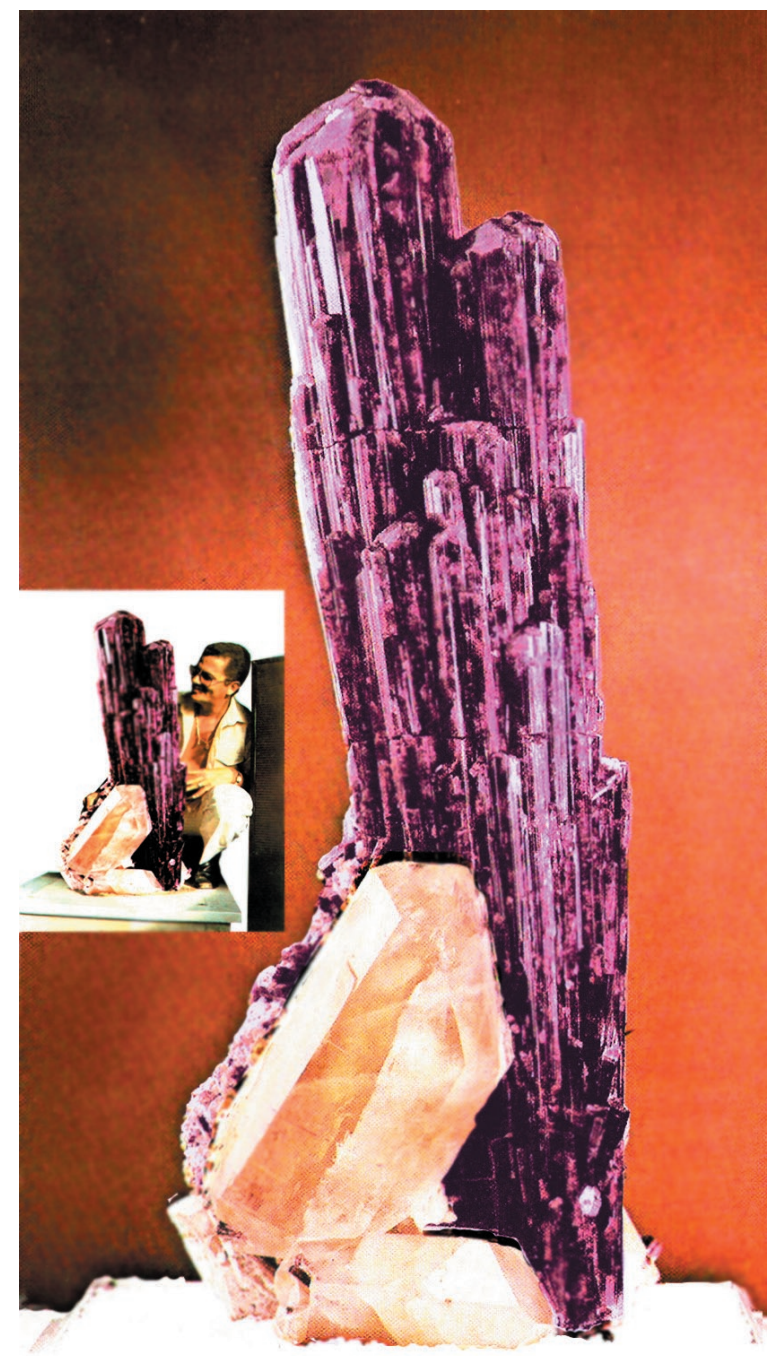

Figura 5: Uma das peças de elbaita vermelha (rubelita) do achado milionário da Lavra do Jonas (Conselheiro Pena - MG) em 1979.

Pesando $130 \mathrm{~kg}$ e apelidada de "Foguete", foi reproduzida em cartão-postal pelo seu descobridor, o garimpeiro já falecido

Ailton Barbosa (detalhe da peça à esquerda).

internacionais suprem os comerciantes varejistas europeus. No Brasil existe um show de gemas (com um pouco também de minerais) em Belo Horizonte - MG, no início de março; outro de minerais, gemas e bijouterias em Soledade - RS, no início de maio; um terceiro de gemas e minerais em Teófilo Otoni - MG, no início de agosto; e um último, principalmente com variedades de quartzo, em Curvelo - MG, em novembro. Em vista de haver poucos colecionadores brasileiros nesses shows, a intenção principal é a venda dos produtos a compradores internacionais.

A amostra de coleção considerada de maior valor unitário até hoje conhecida é um agregado de dois mega-cristais em " $v$ " de elbaíta vermelha (rubelita) sobre matriz de albita, lepidolita e quartzo, produzida em Conselheiro Pena (MG). De estética primorosa e pesando $320 \mathrm{~kg}$, essa peça, apelidada de "Joninha", foi vendida em 1980 a um colecionador particular norte-americano por US\$1,5 milhões (estima-se hoje seu valor de mercado em cerca de US\$ 5 milhões). Junto com esta, foram produzidas outras três amostras excepcionais ("Foguete" - $130 \mathrm{~kg}$, "Tarugo" - $80 \mathrm{~kg}$ e "Flor-de-Lis" - $60 \mathrm{~kg}$ ) (a peça "Foguete" é mostrada na fig. 5), além de centenas de cristais menores, que juntos na época valeram algo próximo de US\$ 3 milhões. De modo semelhante, mas relacionando outro mineral, Cassedanne (1989) relata que em 1987 foi vendido por US\$ 880.000 a outro colecionador norte-americano, um diamante bruto de forma octaédrica e cor vermelha intensa pesando cerca de 1,0 ct (encontrado no Rio Abaeté - MG). Para o citado autor, tal valor representaria a mais valiosa substância natural (e não "trabalhada") já comercializada até hoje, alcançando uma fantástica cifra próxima de US\$ 4,5 milhões por grama!

Interessante ainda destacar que, em função de seus valores, as coleções podem ser classificadas como amadoras (de valor $<$ US\$ 500), pequenas (US\$ 500-5.000), médias (US\$ 5.000-50.000), grandes (US\$ 50.000-500.000) e excepcionais. Neste último caso elas alcançam valores de milhões de dólares. Tem-se conhecimento da existência de somente três dessas mega-coleções no Brasil. O principal problema relacionado a tais coleções é a baixa liquidez que apresentam, bem como a enorme dificuldade em se fazer uma boa avaliação das mesmas. $\mathrm{O}$ valor de uma amostra é aquele que alguém se dispõe a efetivamente pagar. Em geral, quando em vida o colecionador recebe muitas ofertas pelas suas melhores amostras, embora nunca queira ou mesmo pense vendê-las, porém após sua morte essas ofertas não se repetem e os familiares, caso sejam leigos no assunto, dificilmente conseguirão obter o valor que se esperava para tais amostras e muito menos para a coleção inteira.

\section{CONSIDERAÇÕES FINAIS}

O hobby de se colecionar minerais é uma atividade que tem milhões de adeptos no mundo e que, somado à atividade científica de centenas de museus mineralógicos, movimenta várias dezenas de milhões de dólares por ano. Tais atividades incentivam a descoberta e preservação dessas verdadeiras obras-primas da natureza. Além disso, elas permitem a geração de renda e empregos em muitas regiões carentes do Brasil e do mundo. Embora o Brasil ainda seja um grande produtor de minerais de coleção, tal hobby é praticamente desconhecido no país, não havendo mais que algumas centenas de colecionadores. Nossos poucos museus de mineralogia não contam com recursos financeiros para adquirir amostras representativas, o que faz com que praticamente toda a produção das melhores amostras seja destinada ao exterior, representando a perda de um patrimônio científico de grande e não reconhecida importância.

Por outro lado quase toda essa produção é proveniente de atividades garimpeiras. As empresas mineradoras, tão zelosas na condição de suas atividades ambientais, não têm se interessado em estudar ou 
preservar a mineralogia de suas jazidas, significando outra grave perda para nosso patrimônio científico. Grandes empresas operam estações ecológicas, com botânicos, zoólogos e engenheiros florestais, para cadastrarem e preservarem as espécies animais e vegetais das áreas de influência das minas, enquanto provavelmente nenhuma delas possui um mineralogista para evitar a extinção de espécies minerais sem terem antes sido reconhecidas pela Ciência. Como os bens minerais são de propriedade da União, as autoridades responsáveis poderiam requerer às empresas concessionárias que, em paralelo à racional e econômica exploração das jazidas, sua mineralogia fosse também documentada e assim preservada para a posteridade.

Em termos internacionais, a grande maioria das espécies novas descritas a cada ano é proveniente de minas industriais operadas por empresas onde geólogos ou engenheiros de minas se preocupam em coletar as amostras diferentes ou atraentes levando-as à identificação, ou permitem que terceiros possam coletar e estudar esse material. Assim sendo, embora o Brasil seja ainda um grande produtor mineral e possuir enorme potencial, somente oito espécies novas foram aqui descritas nos últimos 20 anos, de um montante quase ínfimo de 48 minerais descobertos a partir de amostras coletadas no país (Atencio, 2000). Nos cinco últimos anos, embora esforços particulares tenham levado à descrição de diversos novos minerais por pesquisadores das universidades de São Paulo e de Brasília (Atencio, 2006), tal número permanece irrisório.

De outro modo, em comparação devem ser citados os casos dos Estados Unidos (620 minerais descritos até meados da década de 1990), Rússia (365 minerais),
Alemanha (250 minerais) e Itália (175 minerais) (conforme Stalder, 1994), países de potencial mineral semelhante ou, mais provavelmente, inferior ao do Brasil. Tal situação poderia ser revertida se houvesse uma mudança radical de posicionamento na classe dos profissionais da área de geociências, acreditando-se que os nossos minerais e ressaltando os minerais de coleção, além de tão importantes como nossa fauna e flora, representam também patrimônios naturais do país, e como tais devem ser convenientemente protegidos.

\section{AGRADECIMENTO}

Este trabalho foi realizado parcialmente com auxílio financeiro da FAPEMIG, Proc. EDT-2244/05, a um dos autores (MLSCC).

\section{REFERÊNCIAS BIBLIOGRÁFICAS}

Atencio D. 2000. Type Mineralogy of Brazil. São Paulo: Museu de Geociências IG-USP, 2000, 114p.

Atencio D. 2006. Minerais brasileiros do século 21. In: Congresso Brasileiro de Geologia, 43, Aracaju. Anais..., p.133.

Betejtin A. 1997. Curso de Mineralogia. Moscou, Editorial Mir, $739 \mathrm{p}$.

Cassedanne J.P. 1989. Diamonds in Brazil. Mineralogical Record, 20:325-336.

Gary M., McAfee Jr. R., Wolf C.L. 1973. Glossary of Geology. Washington, American Geological Institute, 805p.

Mandarino J.A., Back M.E. 2004. Fleischer's Glossary of Mineral Species 2004. Tucson, Mineralogical Record Inc., 309p.

Moore T. 1998. New operations at the Sweet Home Mine, 1990-1997. Mineralogical Record, 21:21-100.

Pinch W.W., Wilson W.E. 1977. Tsumeb minerals: a descriptive list. Mineralogical Record, 8:5-110.

Stalder H.A. 1994. Mineral species first described from Italy. In: International Mineralogical Association General Meeting, 16, Pisa (Italy). Abstracts..., p.391. 